\title{
Pengaruh Suhu Reaksi Pada Proses Hidrasi Alpha Pinene Dengan Katalisator Amberlyst 36
}

\section{The Effect Of Reaction Temperature In Alpha Pinene Hydration Process With Amberlyst 36 Catalyst}

\author{
Norma Eralita $^{1}$, Ayu Pramita ${ }^{2 *}$, Dini Nur Fauziah ${ }^{3}$ \\ ${ }^{1}$ Jurusan S1 Teknik Kimia, Universitas Nahdhatul Ulama Al Ghazali Cilacap, Indonesia \\ ${ }^{2}$ Jurusan D4 Teknik Pengendalian Pencemaran Lingkungan, Politeknik Negeri Cilacap, Indonesia ${ }^{3}$ Jurusan S1 \\ Teknologi Perminyakan, Sekolah Tinggi Teknologi Minyak Bumi dan Gas Cilacap, Indonesia Email : \\ 1norma_eralita@gmail.com, ${ }^{2}$ ayupramita86@politeknikcilacap.ac.id, ${ }^{3}$ dini.nf@gmail.com
}

Direview : 4 Februari 2020

Diterima: 12 Februari 2020

\begin{abstract}
Abstrak
Terpentin Indonesia mengandung 65-85\% $\alpha$-pinene, $1 \%$ camphene, 1-3\% $\beta$-pinene, $10-18 \% 3$ - carene dan 1-3\% limonene. Kandungan terbesar dari terpentin adalah alpha pinene. Alpha pinene juga merupakan senyawa golongan monoterpene yang memiliki ikatan rangkap dan menjadi bahan baku utama dalam industry parfum. Selain itu, alpha pinene juga merupakan bahan baku penting pembuatan fine chemicals yang memiliki nilai jual tinggi seperti minyak pinus (pine oil), camphor dan alpha terpineol. Untuk meningkatkan nilai jual, alpha pinene dapat diolah lebih lanjut menjadi senyawa turunannya seperti alpha terpineol dan alpha terpinyl acetate. Keduanya merupakan senyawa turunan berharga yang digunakan di industri parfum dan industri farmasi. Hidrasi merupakan reaksi antara alpha pinene dengan air menghasilkan senyawa alpha terpineol. Pada proses reaksi yang akan dilakukan terhadap alpha pinene biasanya menggunakan katalisator yang dapat mempercepat laju reaksi tanpa menjadi produk samping, sehingga dalam penelitian ini menggunakan salah satu katalisator yaitu jenis resin penukar kation yaitu Amberlyst 36 wet. Penelitian ini bertujuan untuk mempelajari pengaruh peubah suhu pada suhu $65,75,85$ dan $95^{\circ} \mathrm{C}$. Konversi alpha pinene semakin besar seiring dengan naiknya suhu reaksi. Dengan asumsi reaksi reversible, hubungan suhu terhadap masingmasing konstanta laju reaksi ditentukan sesuai dengan persamaan Arrhenius.
\end{abstract}

Kata kunci: Alpha pinene; Alpha terpineol; Amberlyst 36; Hidrasi .

\begin{abstract}
Indonesian turpentine contains $65-85 \% \alpha$-pinene, 1\% camphene, 1-3\% $\beta$-pinene, 10-18\% 3-carene and 1-3\% limonene. The largest content of turpentine is alpha pinene. Alpha pinene is also a monoterpene compound that has double bonds and is the main raw material in the perfume industry. In addition, alpha pinene is also an important raw material for the manufacture of fine chemicals that have high sales value such as pine oil, camphor and alpha terpineol. To increase the sale value, alpha pinene can be further processed into derivative compounds such as alpha terpineol and alpha terpinyl acetate. Both are valuable derivative compounds used in the perfume industry and the pharmaceutical industry. Hydration is the reaction between alpha pinene and water to produce alpha terpineol compounds. In the reaction process that will be carried out on alpha pinene usually uses a catalyst that can accelerate the reaction rate without becoming a byproduct, catalyst used in this study is a type of resin. This study aims to study the effect of temperature variables at temperatures of $65,75,85$ and $95^{\circ} \mathrm{C}$. The conversion of alpha pinene increase with increasing reaction temperature. Assuming a reversible reaction, the relationship of temperature to each reaction rate constant is determined according to the Arrhenius equation.
\end{abstract}

Keywords: Alpha pinene; Alpha terpineol; Amberlyst 36; Hydration. 


\section{PENDAHULUAN}

Dalam jenis minyak atsiri di Indonesia terdapat 20 jenis yang menjadi komoditi ekspor, di antaranya serai wangi, nilam, akar wangi, kenanga, kayu putih, cengkeh, cendana, pala, kruing, gaharu, lawang dan terpentin. Salah satunya terpentin yang merupakan hasil non hutan yang mengandung getah pinus dari Pinus jenis Merkusii. Terpentin tersebut memiliki hasil atas dan bawah dari proses distilasi yaitu getah pinus dan gondorukem. Gondorukem berupa padatan berwarna kuning jernih sampai kuning tua. Sedangkan terpentin berbentuk cair berwarna jernih serta merupakan pelarut yang kuat. Produk gondorukem dapat diolah lebih lanjut untuk bahan baku industri kosmetik, antiseptik, perekat, cat, dan lain-lainnya. Sedangkan terpentin dapat digunakan untuk bahan baku industri minyak cat, bahan pelarut, isolasi, dan farmasi dan lain-lainnya. Indonesia merupakan negara produsen terpentin terbesar ketiga setelah China dan Brasil. Pengelolaan hutan pinus yang merupakan bahan baku pembuatan terpentin, saat ini ditangani oleh PT Perhutani yang merupakan BUMN dengan tugas menyelenggarakan perencanaan, pengurusan, pengusahaan dan perlindungan hutan. Dari tiga wilayah kerjanya yaitu Jateng (unit I), Jatim (unit II) dan JabarBanten (unit III) dihasilkan terpentin sebanyak 12.000 ton/tahun. Terpentin di Indonesia mengandung $65-85 \%$ a pinene, kurang 1\% camphene, $1-3 \% \beta$ pinene, 10 $18 \%$ 3-carene dan limonene 1-3\%. Di dalam terpentin kandungan terbesarnya adalah $\alpha$ pinene. Alpha pinene adalah suatu senyawa golongan monoterpen yang memiliki ikatan rangkap dan menjadi bahan baku utama dalam industri parfum. Selain itu, $\alpha$ pinene juga merupakan bahan baku penting pembuatan fine chemicals yang mempunyai nilai jual tinggi seperti minyak pinus (pine oil), camphor, dan a terpineol (Fleig, 2010). Beberapa penelitian mengenai hidrasi $\alpha$ pinene menjadi terpineol telah banyak dilakukan. Williams dan Whittaker (1974) mempelajari hidrasi $\alpha$ pinene menggunakan katalis asam asetat hidrat dan asam asetat anhidrat untuk modifikasi $\alpha$ terpineol. Selain menggunakan asam asetat peneliti juga menggunakan asam sulfat dan asam perklorat.

Berdasarkan uraian di atas, maka penelitian di sini akan melakukan variasi suhu reaksi dalam reaksi hidrasi $\alpha$ pinene. Reaksi hidrasi ini secara keseluruhan merupakan reaksi kompleks yang berjalan lambat sehingga peneliti menggunakan salah satu katalis resin padat yaitu Amberlyst 36 untuk mempercepat reaksi tanpa mengubah produk akhir. Amberlyst 36 merupakan salah satu jenis katalis asam padat. Kandungan air pada katalis asam padat Amberlyst 36 (A-36) dilaporkan memiliki pengaruh terhadap efektivitas reaksi hidrasi. Penelitian ini difokuskan pada pengaruh suhu reaksi dengan menggunakan katalis untuk reaksi hidrasi dan memformulasikan perlakuan pada katalis Amberlyst 36 agar diperoleh $\alpha$ terpineol dan $\alpha$ terpinyl acetate yang optimum.

\section{METODE PENELITIAN}

Adapun rangkaian alat yang digunakan dalam penelitian ini disajikan pada Gambar 1. berikut ini.

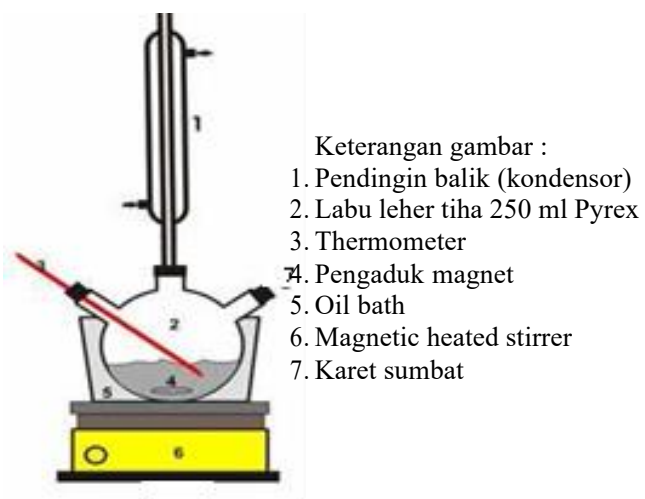

Gambar 1. Rangkaian Alat

Prosedur penelitian dengan variasi suhu reaksi antara lain mula-mula mereaksikan $\alpha$ pinene 99\% dengan larutan asam asetat $75 \%$ dengan katalis Amberlyst 36 wet di dalam reaktor labu leher tiga dengan perbandingan volume 1:1 dan katalis Amberlyst 36 wet sebanyak 5 gram. 
Larutan asam asetat $75 \%$ sendiri dibuat dengan mereaksikan asam asetat glasial $18,75 \mathrm{ml}$ dan $6,25 \mathrm{ml}$ air. Pendingin balik dirangkai bersama dengan labu leher tiga dan kemudian dilakukan pemanasan selama 180 menit di atas hot plate dengan variasi suhu yaitu $65 ; 75 ; 85$ dan $95^{\circ} \mathrm{C}$. Pengambilan sampel dilakukan setiap 30 menit pada variasi suhu reaksi yang diambil.

\section{HASIL DAN PEMBAHASAN}

Berdasarkan hasil yang telah dilakukan dalam penelitian ini yang mencakup data distribusi produk dari reaksi hidrasi pada berbagai konsentrasi produk $\alpha$ terpineol yang maksimum, konversi apinene maksimum dan nilai konstanta laju reaksi dari data konversi apinene pada berbagai suhu.

Variasi suhu dilakukan untuk memperoleh kondisi operasi yang optimum serta mendapatkan harga tetapan kinetika reaksi dari permodelan yang telah dibuat. Untuk mengetahui pengaruh suhu reaksi, penelitian dilakukan pada 4 (empat) titik yaitu $65 ; 75 ; 85$ dan $95^{\circ} \mathrm{C}$. Kondisi perbandingan reaktan 1:1 dan kecepatan pengadukan $\pm 600 \mathrm{rpm}$. Waktu reaksi 180 menit dan setiap 30 menit sampel diambil untuk dianalisis. Konversi $\alpha$ pinene total disajikan dalam tabel 1. Dan Gambar 2. Konversi total yang diperoleh merupakan konversi yang dihitung langsung dari data percobaan. Konversi $\alpha$ pinene dihitung dengan perbandingan $\alpha$ pinene sisa terhadap $\alpha$ pinene mula- mula.

Tabel 1. Konversi $\alpha$ pinene total pada berbagai suhu

\begin{tabular}{|c|c|c|c|c|c|}
\hline No & $\begin{array}{c}\text { Waktu } \\
\text { reaksi } \\
\text { (menit) }\end{array}$ & \multicolumn{4}{|c|}{ Konversi (\%) } \\
\hline & & $\begin{array}{l}\text { Suhu } \\
65^{\circ} \mathrm{C}\end{array}$ & $\begin{array}{c}\text { Suhu } \\
75^{\circ} \mathrm{C}\end{array}$ & $\begin{array}{c}\text { Suhu } \\
85^{\circ} \mathrm{C}\end{array}$ & $\begin{array}{c}\text { Suhu } \\
95^{\circ} \mathrm{C}\end{array}$ \\
\hline 1 & 30 & 74,32 & 80,43 & 79,13 & 82,26 \\
\hline 2 & 60 & 78,49 & 83,11 & 88,28 & 88,28 \\
\hline 3 & 90 & 83,79 & 86,44 & 82,58 & 94,14 \\
\hline 4 & 120 & 85,01 & 87,54 & 89,70 & 96,64 \\
\hline 5 & 150 & 83,62 & 85,85 & 87,07 & 97,31 \\
\hline 6 & 180 & 87,23 & 92,49 & 94,32 & 98,88 \\
\hline
\end{tabular}

Dengan menggunakan software Matlab 7.0 maka pada Gambar 2 menunjukkan bahwa konversi $\alpha$ pinene pada berbagai waktu dan menjelaskan bahwa konversi $\alpha$ pinene meningkat seiring dengan kenaikan suhu. Konversi maksimum yang diperoleh mendekati suhu $95^{\circ} \mathrm{C}$ yaitu sekitar $98,8 \%$.

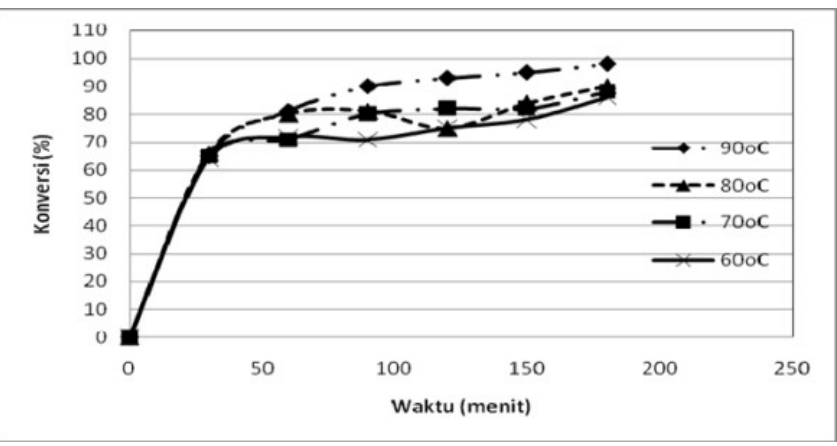

Gambar 2. Konversi $\alpha$ pinene pada berbagai suhu

Pada reaksi ini setiap partikel melakukan pergerakan yang dapat mempengaruhi kenaikan suhu sehingga dapat terjadi adanya energi kinetik partikel yang bertambah. Hal tersebut dapat mengakibatkan timbulnya tumbukan dengan perubahan frekuensi yang meningkat sehingga dapat memungkinkan terjadinya tumbukan yang efektif yang mampu menghasilkan reaksi yang semakin besar. Untuk mengetahui pengaruh suhu terhadap konstanta kecepatan reaksi (laju reaksi) dalam reaksi ini dapat menggunakan persamaan sebagai berikut : 


$$
\begin{gathered}
\mathrm{k}=\mathrm{A} \cdot \mathrm{e}^{-\mathrm{Ea} / \mathrm{RT}} \ldots \ldots \ldots \ldots \ldots \\
\ln \mathrm{k}=\ln \left(A e^{-E a / R T}\right) \\
\ln k=\ln A-\left[\frac{E a}{R}\right]\left[\begin{array}{l}
1 \\
T
\end{array}\right]
\end{gathered}
$$

dimana :

$\mathrm{k}$ adalah konstanta kecepatan reaksi

Ea adalah energi aktivasi $(\mathrm{J} / \mathrm{mol})$

$\mathrm{R}$ adalah konstanta gas $(8,314 \mathrm{~J} / \mathrm{mol} . \mathrm{K})$

$\mathrm{T}$ adalah suhu (Kelvin atau $\mathrm{K}$ )

A adalah faktor frekuensi dan merupakan ukuran probabilitas untuk kemudahan terjadinya tumbukan.

Dengan mensubsitusikan persamaan (1) ke persamaan (3) maka akan diperoleh laju reaksi (konstanta kecepatan reaksi) seperti pada tabel berikut ini.

Tabel 2. Konstanta Laju Reaksi pada Berbagai suhu

\begin{tabular}{|c|c|c|c|c|c|}
\hline No & $\begin{array}{c}\text { Suhu } \\
\left({ }^{\circ} \mathbf{C}\right)\end{array}$ & $\mathbf{k}_{1}$ & $\mathbf{k}_{\mathbf{2}}$ & $\mathbf{k}_{\mathbf{3}}$ & $\mathbf{k}_{\mathbf{4}}$ \\
\hline 1 & 65 & $\begin{array}{c}2,86 \times 10 \\
-1\end{array}$ & $4,3 \times 10^{-3}$ & $1,89 \times 10^{-2}$ & $1,09 \times 10^{-2}$ \\
\hline 2 & 75 & $\begin{array}{c}3,71 \times 10 \\
-1\end{array}$ & $6,3 \times 10^{-3}$ & $1,32 \times 10^{-2}$ & $3,84 \times 10^{-2}$ \\
\hline 3 & 85 & $\begin{array}{c}4,26 \times 10 \\
-1 \\
4\end{array}$ & $2,9 \times 10^{-3}$ & $4,69 \times 10^{-2}$ & $1,78 \times 10^{-2}$ \\
\hline & $\begin{array}{c}4,28 \times 10 \\
-1\end{array}$ & $4,0 \times 10^{-4}$ & $6,38 \times 10^{-2}$ & $3,44 \times 10^{-2}$ \\
\hline
\end{tabular}

Dari tabel 2 di atas menjelaskan bahwa kenaikan konstanta reaksi yang terjadi dipengaruhi oleh kenaikan variasi suhu reaksi. Suhu merupakan faktor penting dalam suatu reaksi kompleks. Saat kenaikan suhu terjadi biasanya akan menyebabkan pergerakan partikel yang semakin aktif dalam suatu reaksi hidrasi. Selain itu akan menimbulkan adanya tumbukan yang sering sehingga menyebabkan konstanta laju reaksi juga semakin besar.

Persamaan (3) tersebut analog dengan persamaan garis lurus yang sering disimbolkan dengan $\mathrm{y}=\mathrm{a}-\mathrm{bx}$ maka hubungan antara energi aktivasi suhu dengan konstanta kecepatan reaksi dapat dianalisis dalam bentuk grafik $\ln \mathrm{k}$ dengan $1 / \mathrm{T}$ dengan gradient $-(\mathrm{Ea} / \mathrm{RT})$ dan intersep $\ln \mathrm{A}$, sebagaimana terlihat sebagai berikut :

$$
\begin{aligned}
& \mathrm{k}_{1}=(42,82) \cdot \mathrm{e}^{-164,9 / \mathrm{T} .} \\
& \mathrm{k}_{2}=\left(4,52 \times 10^{-15}\right) \cdot \mathrm{e}^{-93,81 / \mathrm{T}} \\
& \mathrm{k}_{3}=6,73 \times 10^{-15} \cdot \mathrm{e}^{-58,93 / \mathrm{T}} \\
& \mathrm{k}_{4}=2,82 \times 10^{2} \cdot \mathrm{e}^{-32,80 / \mathrm{T}}
\end{aligned}
$$

Dari persamaan di atas maka dapat diketahui nilai energi aktivasi pada masing-masing konstanta laju reaksi tersebut. Berikut ini nilai energi aktivasinya :

1. Energi aktivasi (Ea) pada $\mathrm{k}_{1}$ sebesar $164,9 \mathrm{~J} / \mathrm{mol}$

2. Energi aktivasi (Ea) pada $\mathrm{k}_{2}$ sebesar $93,81 \mathrm{~J} / \mathrm{mol}$

3. Energi aktivasi (Ea) pada $\mathrm{k}_{3}$ sebesar $58,93 \mathrm{~J} / \mathrm{mol}$

4. Energi aktivasi (Ea) pada $\mathrm{k}_{4}$ sebesar $32,80 \mathrm{~J} / \mathrm{mol}$

Berikut ini grafik hubungan antara ln $\mathrm{k}$ dengan $1 / \mathrm{T}$.

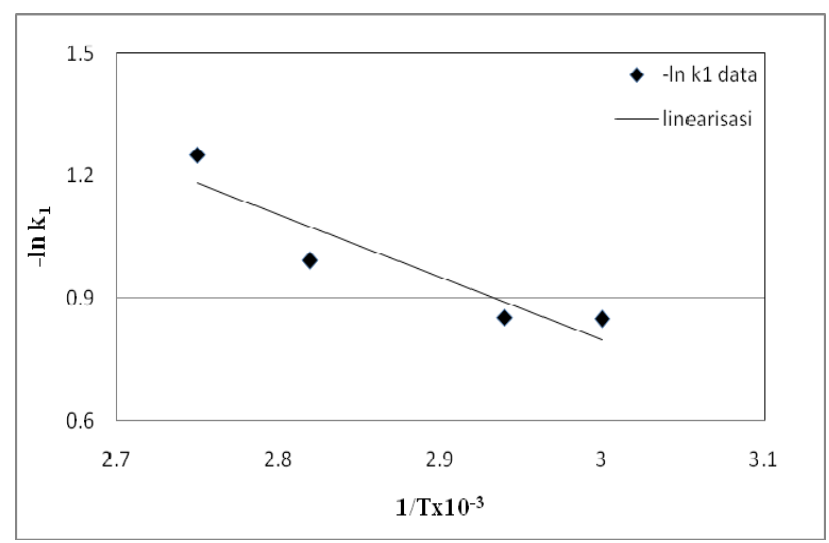

Gambar 3. Hubungan $\ln \mathrm{k}_{1}$ dengan $1 / \mathrm{T}$ 


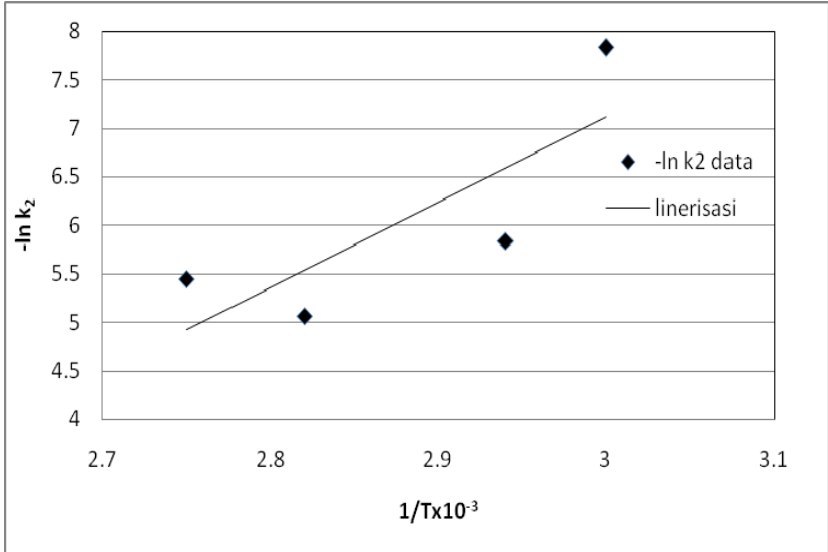

Gambar 4. Hubungan $\ln \mathrm{k}_{2}$ dengan $1 / \mathrm{T}$

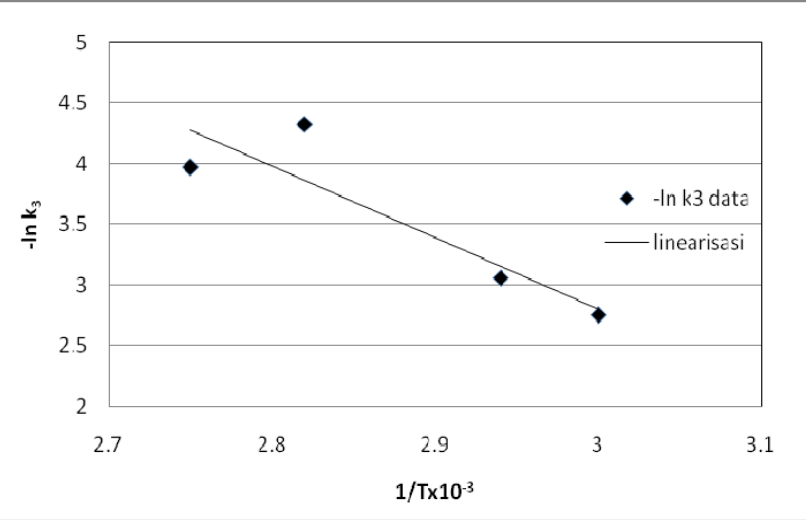

Gambar 5. Hubungan ln $\mathrm{k}_{3}$ dengan $1 / \mathrm{T}$

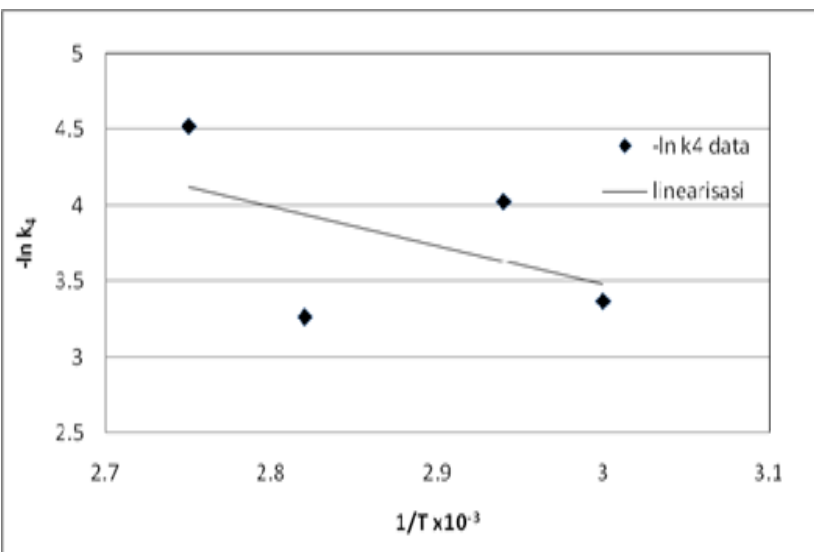

Gambar 6. Hubungan $\ln \mathrm{k}_{4}$ dengan 1/T

Dari grafik di atas menunjukkan bahwa hubungan suhu dengan konstanta kecepatan reaksi dapat mempengaruhi hasil reaksi yang dapat menimbulkan adanya produk samping yang dihasilkan (byproduct) namun tidak mempengaruhi produk $\alpha$ terpineol.
Dari konstanta kecepatan reaksi, terlihat semakin tinggi suhu maka nilai $\mathrm{k}_{2}$ semakin besar. Dengan semakin besarnya nilai $\mathrm{k}_{2}$ maka akan semakin besar laju pembentukan $\alpha$ terpineol dan $\alpha$ terpinyl acetate. Namun berbeda halnya dengan nilai $\mathrm{k}_{1}, \mathrm{k}_{3}$, dan $\mathrm{k}_{4}$ yang diperoleh dimana semakin tinggi suhu maka nilai $\mathrm{k}_{1}, \mathrm{k}_{3}$, dan $\mathrm{k}_{4}$ akan semakin kecil. Karena persamaan laju reaksi didefinisikan dalam bentuk konsentrasi reaktan maka dengan naiknya konsentrasi maka naik pula kecepatan reaksinya. Artinya semakin tinggi konsentrasi, maka semakin banyak molekul reaktan yang tersedia.

Sebelum suatu tumbukan terjadi, partikel-partikel memerlukan suatu energi minimum yang disebut energi pengaktifan atau energi aktivasi $(\mathrm{Ea})$. Energi pengaktifan atau energi aktivasi adalah energi minimum yang diperlukan untuk berlangsungnya suatu reaksi. Ketika reaksi sedang berlangsung akan terbentuk zat kompleks teraktivasi. Zat kompleks teraktivasi berada pada puncak energi. jika reaksi berhasil, maka zat kompleks teraktivasi akan terurai menjadi zat hasil reaksi.

\section{KESIMPULAN}

Berdasarkan hasil dan pembahasan di atas maka dapat diambil kesimpulan bahwa :

1. Proses reaksi hidrasi $\alpha$ pinene merupakan reaksi reversible karena semakin banyak kandungan air dalam larutan yang terbentuk semakin besar pula konsentrasi produk $\alpha$ terpineol yang terbentuk serta semakin sedikit pula produk oligomerisasi dan isomerisasi yang terbentuk.

2. Semakin lama waktu reaksi yang terjadi maka semakin meningkat konversi dan semakin tinggi pula suhu reaksi maka semakin besar nilai konversinya, sehingga suhu optimum yang diperoleh pada saat $95^{\circ} \mathrm{C}$. Sedangkan waktu optimum untuk memperoleh selektivitas produk $\alpha$ terpineol dan $\alpha$ terpinyl acetate tertinggi pada menit ke 60 .

\section{DAFTAR PUSTAKA}

Estuti,P.,2011,"Transformasi $\alpha$ pinene Melalui Reaksi Hidrasi Menggunakan Katalis Asam dan Zeolit Teraktivasi”, Tugas Akhir II, FMIPA-UNNES,Semarang. 
Harnani, 2010, "Perbandingan Kadar Eugenol Minyak Atsiri Bunga Cengkeh (Syzgium aromaticum (L.).Meer \& Perry) dari Maluku, Sumatera, Sulawesi dan Jawa dengan Metode GC-MS:, Skripsi,FarmasiUMS,Surakarta.

Pratiwi, 2011,"Optimalisasi Reaksi Esterifikasi Asam Asetat dengan 1-Heksena Sebagai Salah Satu Tahapan Pada Proses Pembuatan Etanol", Tesis, fakultas Sains dan Teknologi, Universitas Islam Negeri Syarif Hidayatullah,Jakarta.

Yadav, and Jasra,2009, "Acetoxylation and Hydration of Limonene and $\alpha$ Pinene Using Cation exchanged Zeolite Beta", Journal of Molecular Catalysis

A Chemical,297,pp.101-109.

Yang, Zhou and Zhang, 2011, "Kinetic Study of The Direct Hydration of Turpentine", Chemical Engineering Journal, 168,pp.351358

Wijayati,Ranowo dan Triyono, 2011, "Synthesis of Terpineol from a pinene Catalyzed by TCA/Y-Zeolite", Indonesian Chemical Journal, 11,pp.234-237. 
Jurnal Pengendalian Pencemaran Lingkungan (JPPL)

Vol.2 No.01 Maret 2020

DOI : 10.35970/jppl.v2i1.136

Corresponding Author : ayupramita86@politeknikcilacap.ac.id 